\title{
The scalloped gene encodes a novel, evolutionarily conserved transcription factor required for sensory organ differentiation in Drosophila
}

\author{
Shelagh Campbell, ${ }^{1,2}$ Maneesha Inamdar, ${ }^{3}$ Veronica Rodrigues, ${ }^{3}$ Vijay Raghavan, ${ }^{3}$ \\ Michael Palazzolo, ${ }^{4}$ and Arthur Chovnick ${ }^{1,5}$ \\ ${ }^{1}$ Department of Molecular and Cell Biology, University of Connecticut, Storrs, Connecticut 06269-2131 USA; \\ ${ }^{3}$ Molecular Biology Unit, Tata Institute of Fundamental Research, Homi Bhabha Road, Colaba, Bombay 400005, India; \\ ${ }^{4}$ Department of Genetics, Washington University Medical School, St. Louis, Missouri 63110 USA
}

The scalloped (sd) gene of Drosophila melanogaster was initially characterized by mutants affecting structures on the wing of the adult fly. The sequence of a cDNA clone of the gene reveals a predicted protein sequence homologous to that of a human transcriptional enhancer factor, TEF-1 (68\% identity). The homology includes a sequence motif, the TEA domain, that was shown previously to be a DNA-binding domain of $T E F-1$. An sd enhancer trap strain expresses the reporter gene in a subset of neuroblasts in the central nervous system and in the peripheral sense organs of the embryo. The reporter gene is later expressed in specific regions of the imaginal discs, including regions of the wing disc destined to become structures defective in viable $s d$ mutants. Later still, expression in the adult brain is restricted to subsets of cells, some in regions involved in the processing of gustatory information. These observations indicate that the $s d$ gene encodes a transcription factor that functions in the regulation of cell-specific gene expression during Drosophila development, particularly in the differentiation of the nervous system.

[Key Words: Drosophila; scalloped gene; TEF-1]

Received December 5, 1991; revised version accepted January 3, 1992.

One approach to identifying genes with roles in the development and function of the nervous system is to characterize mutants with phenotypic defects affecting the external sensory organs. Hypomorphic mutations in the scalloped $(s d)$ gene of Drosophila melanogaster affect the morphology of the adult wing (Gruneberg 1929). This phenotype involves the loss of sensory structures that normally comprise the wing margin, creating a gapped or scalloped appearance. The phenotype is similar to that of mutant alleles of several genes with demonstrated roles in neural development: cut (Bodmer et al. 1987), Notch (Campos-Ortega and Knust 1990; Xu et al. 1990), and Serrate (Fleming et al. 1990; Thomas et al. 1991). In addition to margin defects, $s d$ mutants often develop ectopic macrochaetae on the wing blade /Campbell et al. 1991). This aspect of the $s d$ mutant phenotype is similar to that of other genes with regulatory functions in neural development: hairy (Rushlow et al. 1989), shaggy/zw-3 (Perrimon and Smouse 1989; Simpson and Carteret 1989) and extramacrochaetae (Garcia Alonso and Garcia-Bel-

\footnotetext{
${ }^{2}$ Present address: Department of Biochemistry, University of California, San Francisco California 94143-0448 USA

${ }^{5}$ Corresponding author.
}

lido 1988). A cell-autonomous $s d^{+}$function is required during larval development for normal wing development (Simpson et al. 1981). Histological analysis of a viable $s d$ mutant indicates elevated cell death in larval wing discs, suggesting that the adult wing phenotype is the result of loss of precursor cells of the wing margin (James and Bryant 1981). Cell autonomy of the wing function may mean that products of this gene act in the reception or implementation of developmental signals. Lethal $s d$ alleles that die either as early larvae or during pupal development have been characterized, and all but one of these fails to complement the wing phenotype in transheterozygote combinations with different viable $s d$ alleles (Campbell et al. 1991). Recently, it has been found that viable $s d$ mutants also show abnormal responses to gustatory stimuli (Anand et al. 1990).

The $s d$ gene was cloned by transposon tagging with a $P\left[\mathrm{ry}^{+}\right]$insertion mutation and chromosome walking (Daniels et al. 1985; Campbell et al. 1991). Viable and lethal $s d$ mutations were mapped within a $\sim 14-\mathrm{kb}$ genomic region, and structurally related, developmentally regulated transcripts hybridizing to this region were characterized (Campbell et al. 1991). cDNA clones representing three transcript classes were identified that are 
presumed to arise by alternative RNA splicing of a $\sim 12$ $\mathrm{kb}$ primary transcription unit. In this report we describe the sequence and exon structure of a cDNA clone representing one of these $s d$ transcripts. The potential translation product of this $s d$ cDNA clone includes a highly conserved sequence motif described recently as the "TEA domain," proposed to be the signature of a new family of DNA-binding proteins (Bürglin 1991).

We have found an $s d$ enhancer trap strain that has a $\beta$-galactosidase reporter gene inserted within an intron of the $s d$ gene. The reporter gene is expressed in cells of the central nervous system (CNS) and peripheral nervous system (PNS) in a dynamic and complex pattern. These observations suggest that $s d$ participates in a regulatory network controlling the differentiation of the nervous system. We discuss these findings and directions for future studies.

\section{Results}

An sd cDNA clone encodes a homolog of the human transcription enhancer factor gene, TEF-1

The E21 cDNA clone sequenced in this study was recovered from an embryonic cDNA library probed with genomic DNA from a region altered in several lethal $s d$ alleles (Brown and Kafatos 1988; Campbell et al. 1991). The E21 clone is 2938 bp in length and hybridizes to genomic DNA fragments extending across a $\sim 12-\mathrm{kb}$ genomic region that encompasses the genomic interval affected by DNA lesions in a number of different viable and lethal $s d$ mutations. The sequence of the E21 cDNA clone is presented in Figure 1. A large open reading frame (ORF) of $1323 \mathrm{bp}$ is found in this sequence, and a translation of the ORF is shown in Figure 1. We have used PCR amplification of genomic DNA to demonstrate that one of the lethal $s d$ mutants, $1(1) s d^{47 M}$, has a $\sim 100$-bp deletion that would truncate the E21 clone within the ORF described in Figure 1 (see Fig. 3, below, for the genomic location of this deletion). The $1(1) s d^{47 M}$ allele is one of two larval-lethal $s d$ alleles, suggesting that the translation product encoded by the E21 cDNA clone is required for an early essential sd function.

The 440-amino-acid protein sequence encoded by the ORF of the E21 clone was compared with sequences in the GenBank data base, and a single significant match was found that involved a stretch of 46 amino acids in a gene cloned from Aspergillus nidulans called abacus $A$ ( $a b a A$; Mirabito et al. 1989). This sequence is part of an evolutionarily conserved motif, the TEA domain, that has been found recently in genes from two additional organisms, the TEC-1 gene from Saccharomyces cerevi- siae (Laloux et al. 1990), and the human transcription enhancer factor, TEF-1 (Xiao et al. 1991). Among the four identified members of this new class of genes, the TEA domain of $s d$ is most closely related to that of the human gene TEF-1 (70/72 residues, 98\% identical). In comparison, the TEC- 1 and abaA proteins are only $44 \%$ and $65 \%$ identical to TEF-1 over the TEA domain, respectively (Bürglin 1991). The DNA-binding domain of the TEF-1 protein corresponds to the conserved TEA domain (Xiao et al. 1991).

Sequence conservation between $s d$ and TEF-1 extends beyond the TEA domain and includes almost the entire predicted protein sequence (Fig. 2). Allowing for gaps to maximize the alignment between TEF-1 and scalloped predicted protein sequences, we observe $68 \%$ identical amino acids and $81 \%$ similar amino acids over the entire aligned sequence. The predicted $s d$ protein includes an additional 51 amino acids at its $5^{\prime}$ end relative to the TEF-1 protein but is predicted to end at an identical carboxyl-terminal residue (Fig. 2). Both TEF-1 and the $s d$ predicted protein sequence have serine-rich amino-terminal regions, followed by the basic TEA domain. A proposed "finger" motif at the carboxyl terminus of the $T E F-1$ gene is only partially conserved in the $s d$ sequence (see legend to Fig. 2).

\section{Structure of the sd transcription unit}

To determine the structure of the transcript represented by the E21 clone, DNA clones of $s d$ genomic restriction fragments that hybridize to it were sequenced and the genomic and cDNA sequences were aligned to identify the boundaries of exon and intron domains. The E21 clone has 12 exons whose positions relative to the genomic map are shown in Figure 3 (see also Fig. 1 for the positions of intron/exon boundaries within the cDNA sequence). The sequence data agree with previous estimates based on genomic hybridization analysis in showing that the primary $s d$ transcription unit extends $\sim 12$ $\mathrm{kb}$ on the genomic map, as shown in Figure 3. Conventional splice site usage (Mount 1982) was observed at the intron/exon boundaries of the E2l clone (data not shown).

The $5^{\prime}$ end of the E21 clone begins at the same genomic position as another $s d$ cDNA clone, D16, and both have a $G$ residue at their $5^{\prime}$ end that is not genomically encoded. This feature has been noted for previously characterized complete cDNA clones isolated from this library and is thought to be a cloning artifact that occurs when the reverse transcriptase attempts to copy the 7-methylguanosine cap of the mRNA during synthesis of the cDNA library (Brown et al. 1989). These observations

Figure 1. cDNA and deduced amino acid sequence of the $s d$ E21 cDNA clone. The nucleotide and deduced amino acid sequences of the large ORF of the E21 cDNA clone are indicated. The nucleotide sequence was determined from both DNA strands, and regions of sequence compression were sequenced with dideoxynucleotides to resolve ambiguities. The amino-terminal TEA domain is underlined. Positions of intron and exon boundaries were determined by sequencing of overlapping genomic clones, and these positions are indicated along the sequence (exons begin immediately under the e of exon in each case). The position of a potential mRNA destabilization signal (AUUUA) in the $3^{\prime}$ UTR of the E21 clone is indicated by underlining. The DNA sequence of $s d$ E21 has been deposited in the GenBank data base under accession number M83787. 
exon 1

GAGTOGATGA GTTCTCTCG CTTCTGCGOG TGGGTITI CGCAGTGTT COGCGATTI TCGTTGTCGT CATCGTGT TCGTTGCCT CGTGTTGTG TGTGGTGTAT

\begin{tabular}{l} 
exon 2 (203) \\
\hline
\end{tabular}

TGTGAGTGOG OOOCOOGTTG OCGITGOCAC CACOGCAGAC GOCTOCOOOC CCTTIITTT TIGCTGGCTA CAGCOGTGAG COCTGTAAAA GTATCTTTCT CACTTCCTAA exon 3 (258)

gAACTCOGAA OCAATTCATG AATTATTGCA GATGTGAATA ATAACAOGCC CAGCOCAGAG OCTGA ATAACAAGAG TGAGTGCCT GOCTTGGACC AGOOGGAGAC GACAACAACG IITGATGTTG TGGTGGAGA OGGTGACATC AGAGTCTAAA TCTAGOGCGA ACAGATTTCT TITAATOCG TAAACTAAGT GGACAACGCA COGTACTOGT ACCOCACTCG TTCCGTACTC GTTCTCGTAC TCGAAGTCGT ATTCCTATTC CTOOOGGOOGG GCATACTCGT 596

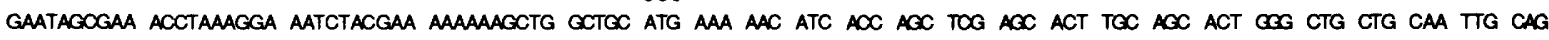

Det lys Asn lle Thr Ser Sor Ser Thr Oas Ser Thr Gly Leu Leu Gln Leu Gin exon $4(705)$

AAC AAC CTG AGC TOC AGC GAG TTG GAA GTT COC GAG AAG ACA GAA CAA CAG GCA GTT GGA OOC GSC AOC ATA OCA TCA OOG TGG ACA OCA

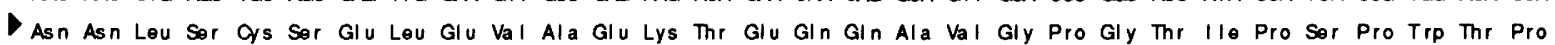

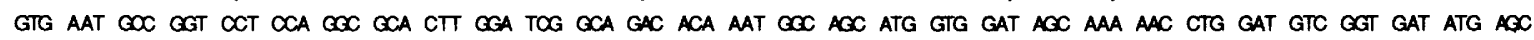

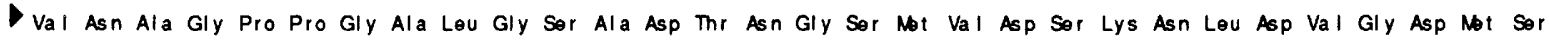
exon 5 (833) 88

GAT GAC GAA AAG GAC TTG TCA TOC GCT GAT GOC GAA GGT GTA TGG AGT OCA GAT ATC GAG CAG ASC TTT CAA GAG GCT TTA TCT ATA TAT

- Asp Asp glu lys asp leu Ser Ser Ala Asp Ala Glu Gly val Trp Ser Pro Asp Ile Glu Gin Ser the Gin Glu Ala Leu Ser Ile Tyr

exon 6 (972)

COG OOG TGC GGA CGT AGA AAA ATC ATT TTA TOC GAC GAG GGT AAA ATG TAC OGT OOC AAC GAG CTA ATC GCA CGA TAT ATA AAA CTG OOC

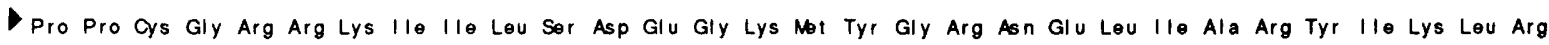

159

ACA GOC AAA AOG AGA AOC AGG AAG CAA GTC AGT TOG CAC ATC CAA GTG CTG GCT OOC OGT AAA CTC OOC GAG ATC CAG GOG AAA ATC AAA

Thr Gly Lys Thr Arg Thr Arg Lys Gln Val Ser Sor His lle Gln Val Leu Ala Arg Arg Lys Leu Arg Glu Ile Gln Ala Lys Ile Lys

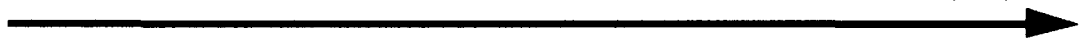

exon 7 (1103)

exon 8 (1144)

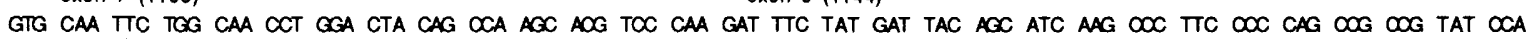

- Val gin phe trp gin Pro gly leu Gin Pro Ser Thr Ser Gin Asp Phe Tyr asp Tyr Ser lle Lys Pro Phe Pro Gln Pro Pro Tyr Pro GCT COC AAA AOG TOG ACT GOG GTT TOC GOG GAC GAA ACT GGA ATT OOG OOC TCA CAA TTG COC TGG GAA OGA OGA GOC ATT GOC AOG CAC

- Ala Gly lys Thr Ser Thr Ala Val Ser Gly Asp Glu Thr Gly lle Pro Pro Ser Gin Leu Pro Trp Glu Gly Arg Ala Ile Ala Thr His exon 9 (1334)

AAA TTC OOC TTA CTC GAG TTT ACG GOG TTC ATG GAA ATC CAG AGA GAT GAA ATT TAT CAC OCG CAT CTA TTC GTT CAA CTT GCC GCC AAG

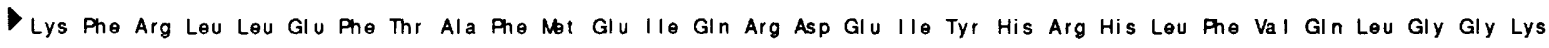
exon 10 (1397)

OCA TCC TTT TOC GAT CCA TTG CTT GAG ACT GTT GAT ATA OOG CAA ATA TTC GAC AAG TTT COG GAG AAA TCT GCG GCC CTT AAA GAT CTC

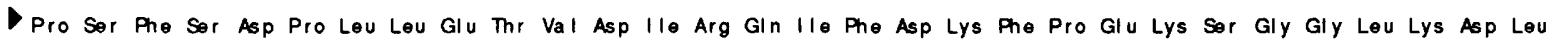

TAC GAA AAG GGT OCA CAG AAT GOG TTT TAC CTA GTT AAA TGC TGG GOG GAC CTG AAT ACC GAT CTA ACA AOC GCC ACC GAA ADG GGT GAT

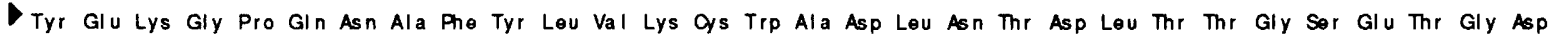
exon $11(1570)$

TTC TAT GOC GTA AOC AGC CAA TAC GAA AGC AAC GAG AAT GTC GTG CTC GTG TGC TOC ACA ATC GTT TCC TOC TTT GOC AAG CAA GTG GTG

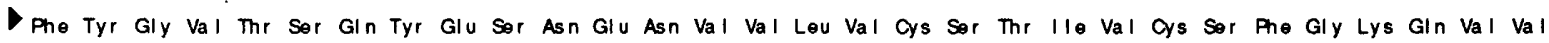
GAG AAG GTG GAA AGC GAG TAC TOC OGA CTG GAG AAC AAT OCC TAC GTC TAT OOC ATT CAA OOC TCC OOC ATG TGC GAG TAC ATG ATC AAC

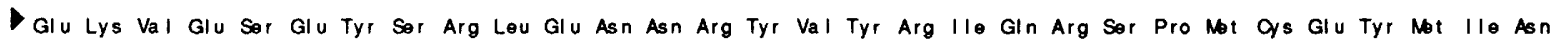
exon 12 (1805)

TTT ATT CAG AAG CTG AAG AAC CTA OOG GAA OCC TAT ATG ATG AAC AGT GTG CTG GAA AAC TTT ACA ATA TTG CAA GTA ATG

- Phe lle gin lys leu lys asn leu pro glu arg tyr not not asn ser Val lou glu asn phe thr lle leu gin val met arg ala arg GAG AOG CAG GAG ACA CTG TTG TGC ATA GOC TAT GTG TTT GAG GTG GOG GOC CAG AAC AGC GGC AOC ACC CAT CAC ATA TAC OGT CTA ATT

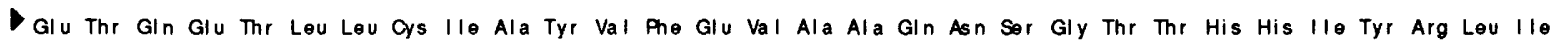
1916

AAG GAA TAG CAAAGCTGC ATGGAGCAGA ACOCAACCTG TCTGCGAATC CCATCATCAA CACACAAGTT CACAAATATA COGACAACAA CAACAGCAGC AGCATCAACA

D Lys GIu ...

ATAATAGTAT CATCAATACG GCTAAGAATT GCGATAATAA GACGAGTAAT GAAATTGOCA ACACAATATC CAACACCAAG AGTGCCAGAA TCATCAGCAG TATCAACAGC ATCAACAACA CCAGCAACAT $\cong G G C A A C A T C$ AGCAACAATA GCAACACTAT CGCACTAAAA TGTGGOGACG GCAATATGAA AACCAGGAAC CTATCOGTTG CTGGCGOCAC AATTATCAAG CAATCACTCA OCTCACCGCA ACATCATACG GATATCGATG CCTTGACAGC ACTTCAAGTG GAGGAGGTTA TTTATACACA GTCACAAGGG AATACCAGTT ATCAATTAGA CACCGAACA AGCATTGCTC CCAACGTACA AGAGOCAACA CTCCAGCAGC AACATACOGC CTATGAGGAT OGTACAGTGA CAGTCCTGCC ACCGTATAAT CTATGTATCG GCAACAAGCA ACCACAACCA TTCGAGCCTG AGCAACACGA ACACGAACAC GAOCAGGAAC AGGAACTGGA ACAGGAACTG GATCAGGAAC AGCAGAACCA ACTGGGGAAC ACGGGCTATG AGCAGTTOCT GAAGTTGTCC GCTCATGAAT ATTCAGAAAC TGACAGACGT OOGCGGCTGC TCTAAATCTC AGCAGTATTG GCGAAAAGA AGOGGCATTG GTCGGTGAAT OCAAGAOGGA TCTTGAAGAT COGOCAGAGT TTCGGATGCT TOGAGAGGTC AGTGCGACAG OGQOGGAGGA TOCAOGACGA GGACOCAAOG COGATGGAAT CAGTAACAAA GGOOGTGAGC OGTGAGOGOC ATATAATACC ACCAGCCTIT AAGCAAGGTT GAGGCTTATT TTAAGGGTTA GAAATACGAT TGCAAGGAAC GACACAATCA GAGCTITTTG TITTCCACCC AAAACGAG

Figure 1. (See facing page for legend.) 
Campbell et al.

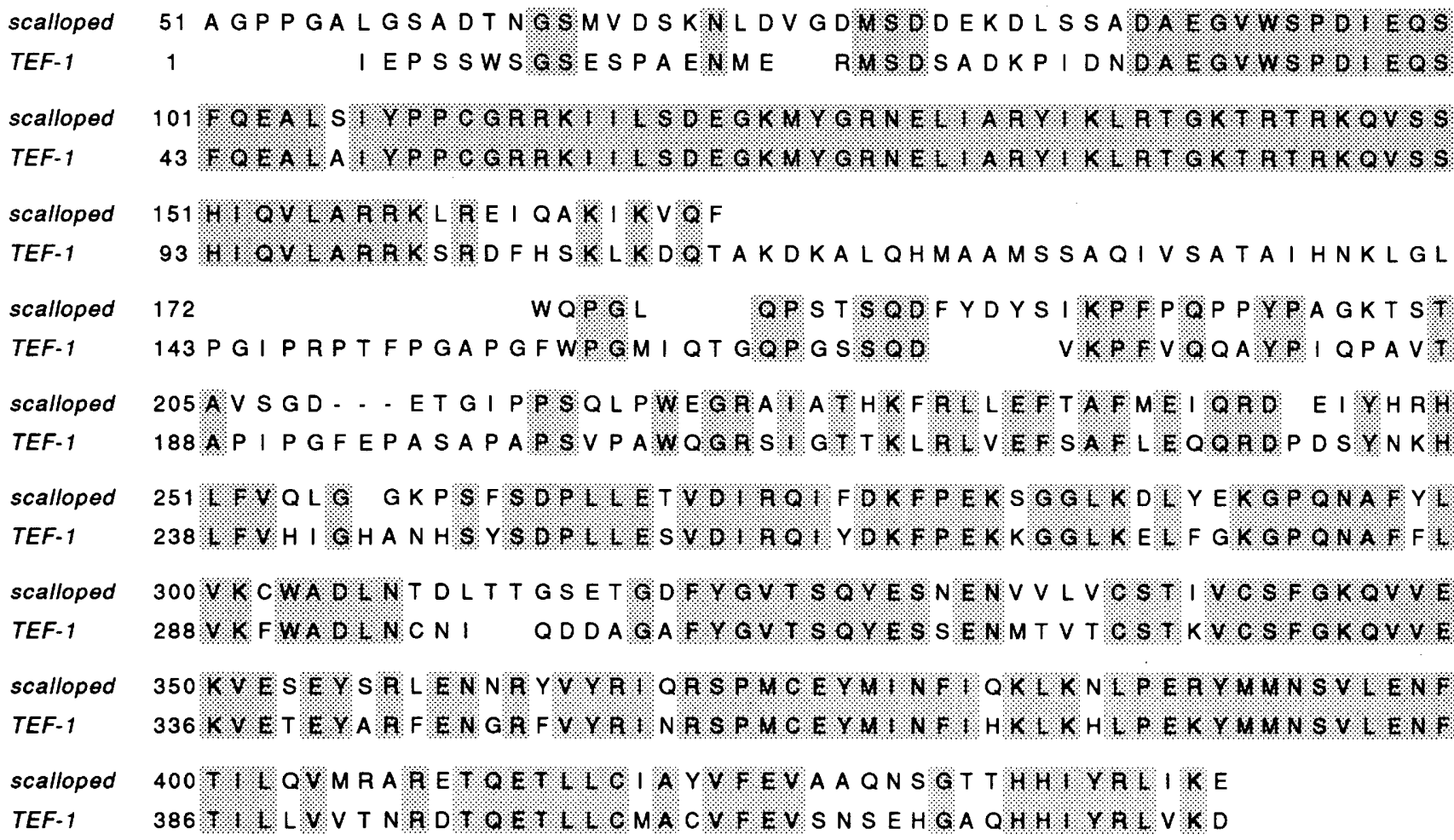

Figure 2. Comparison of $s d$ - and TEF-1-predicted protein sequences. The predicted amino acid sequence of the $s d$ E21 clone and of the protein TEF-1 (Xiao et al. 1991) are compared, allowing for gaps to optimize the alignment. Shading is used to indicate identical amino acids in the aligned regions. The TEA domain is found between amino acids 88 and 170 of the sd sequence. An incomplete version of a putative finger motif found at the carboxyl terminus of the TEF-1 sequence (Xiao et al. 1991) is located in the $s d$ sequence beginning at amino acid 416: $\mathrm{C}_{416} \mathrm{X}(15) \mathrm{H}_{432} \mathrm{H}_{433}$.

suggest that the $5^{\prime}$ end of the $s d$ transcription unit is represented by the $5^{\prime}$ end of the E21 cDNA clone.

The E21 clone is probably incomplete at its $3^{\prime}$ end, because it is lacking a poly $(\mathrm{A})^{+}$tail and is shorter than $s d$ transcripts observed by RNA hybridization analysis (Campbell et al. 1991). The TEF-1 and $s d$ cDNA clones are both associated with unusually long $3^{\prime}$-untranslated regions (UTRs) that include at least one copy of a putative mRNA degradation motif (AUUUA; Brawerman 1989; Xiao et al. 1991). The motif found in the $s d 3^{\prime}$-UTR sequence is underlined in Figure 1 . We have not attempted to quantify the stability of $s d$ transcripts directly but note that the signal from total animal poly $(\mathrm{A})^{+}$RNA is very weak (Campbell et al. 1991).

The predominant $s d$ transcripts are 4.5 and $3.3 \mathrm{~kb}$ in size (Campbell et al. 1991). Sequencing of three different $s d$ cDNA clones indicates that some of the observed transcript heterogeneity is attributable to alternative splicing of a primary transcription unit in the $5^{\prime}$ and $3^{\prime}$ UTRs. Sequencing of different TEF-1 cDNA clones also suggests that this gene is alternatively spliced in its $5^{\prime}$ UTR (Xiao et al. 1991).

The positions of two transposon insertions associated with $s d$ mutations have been determined by genomic hybridization analysis. Neither of the insertions would interrupt the coding region of the E21 transcript, and these $s d$ mutants are viable. The $s d^{r y+E T X 4}$ allele is a transposon insertion carrying a $\beta$-galactosidase reporter construct situated in the first intron (Fig. 3; Anand et al. 1990). This insertion appears to place the reporter gene under the influence of $s d$ regulatory sequences, as discussed below. The $s d^{r y+}$ allele (also called $s d^{p[r y+2216]}$ is associated with a $P[r y+]$ transposon insertion situated 500-600 bp upstream from the 5' end of the E21 cDNA clone (Daniels et al. 1985). A number of other viable $s d$ mutations associated with $P$-element insertions have also been localized to a $\sim 2-\mathrm{kb}$ genomic interval that includes the region around the $5^{\prime}$ end of the E21 cDNA clone (Campbell et al. 1991). It has been noted before that $P$-element insertions are often clustered in the $5^{\prime}$ regulatory regions of genes (Engels 1989), and it appears that the $s d$ gene provides another example of this phenomenon.

There do not seem to be any other vital genes within a $10-\mathrm{kb}$ genomic interval upstream of the $5^{\prime}$ end of the E21 transcript. This conclusion is based on the viable phenotype of a hybrid dysgenesis-induced $s d$ allele called $s d^{93}$ that is associated with a deletion of genomic DNA sequences extending leftwards from the zero $(0)$ coordinate on the genome map (Fig. 3; Campbell et al. 1991). Although it is viable, the $s d^{93}$ mutant does have an extreme wing phenotype, perhaps indicating the presence of $s d$ regulatory sequences in this region. Downstream of the $s d$ transcription unit, a Drosophila homolog of the clath- 


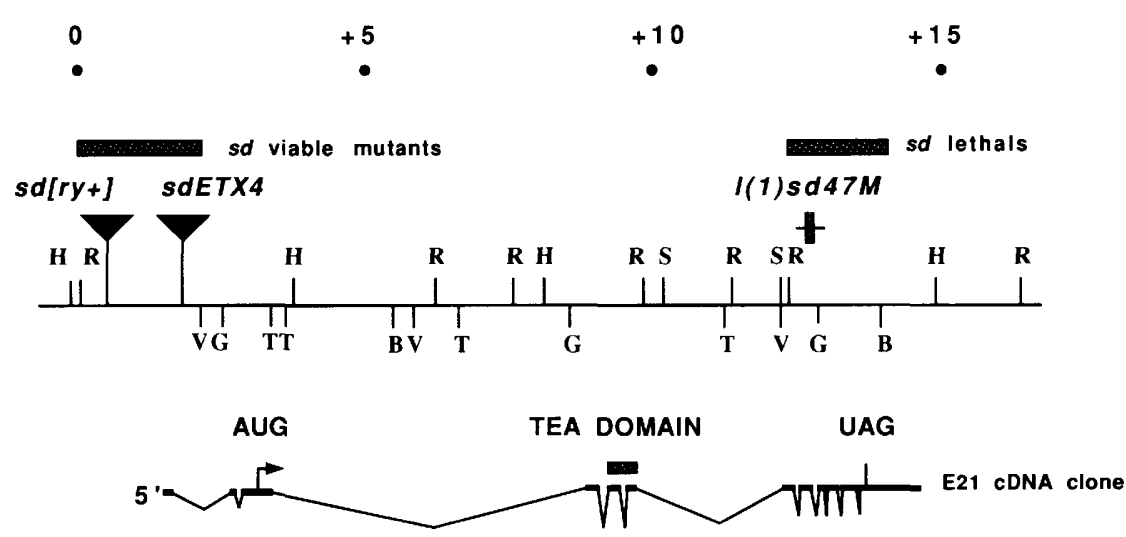

$s d^{p[r y+1}$ (Daniels et al. 1985) and $s d^{P / x y+l a c z+E T Z X 4)}$ (Anand et al. 1990), are shown on the genomic map. The approximate position of a $\sim 100$-bp deletion associated with the larval-lethal mutant, $1(1) s d^{47 M}$ (Campbell et al. 1990) is indicated. The deletion is located between +12 and $+12.4 \mathrm{~kb}$ on the genomic map. Three other $s d$ lethal alleles have been mapped by denaturing gradient electrophoresis to genomic region +12 to $+14.1 \mathrm{~kb}$ as well (Campbell et al. 1991).

rin heavy-chain gene has been localized $\sim 2 \mathrm{~kb}$ from the 3 ' end of the E21 cDNA clone and is transcribed in the opposite orientation (C. Bazinet, pers. comm.).

\section{Wing defects in sd mutants}

The Drosophila wing offers a relatively simple and accessible system for studying the development of the PNS. It has a highly reproducible pattern of sensory organs, whose neural projections to the CNS have been mapped and developmentally characterized (Palka et al. 1979; Murray et al. 1984; Hartenstein and Posakony 1989, 1990). Genetic mosaic studies indicate that commitment to form sensory bristles occurs during larval development well before these structures emerge during pupal development (Garcia-Bellido and Merriam 1971; Poodry 1975; Garcia Alonso and Garcia-Bellido 1988; Ripoll et al. 1988; Hartenstein and Posakony 1989).

The most obvious aspects of the $s d$ viable mutant phenotype involve aberrant structures on the wing, particularly the loss or gain of sensory bristles. An example of a wild-type wing is shown in Figure 4A. Viable hypomorphic $s d$ mutants can be arranged in an allelic series with respect to the wing phenotype, ranging from slight nicking of the margin (see Fig. 4B), more extensive nicking (Fig. 4C), to the complete erosion of the margin and a drastic reduction of the surface area of the wing blade (Fig. 4D). Ectopic sensory bristles (macrochaetae) are also seen on the wing blades of many (but not all) $s d$ alleles (Fig. 4B,C).

The anterior margin of a wing is normally lined with rows of macrochaetae or sensory bristles, which are the cuticular external components of mechanosensory and chemosensory organs (Murray et al. 1984; Hartenstein and Posakony 1989). To examine these structures, scanning electron microscopy (SEM) was employed. The appearance of macrochaetae along the anterior margin of a wild-type wing and an $s d$ mutant wing are shown in Figure 5. A highly ordered array of macrochaetae is apparent on the anterior margin of a wild-type wing (Fig.
5A) in contrast to the disordered array in an $s d$ mutant (Fig. 5B). We also examined the appearance of ectopic bristles on the wing blades of $s d$ mutants. Mechanosensory organs called campaniform sensilla are normally found at distinct locations on the blade of the wing, an example of which is shown in Figure 5C (Dickinson and Palka 1987). An ectopic bristle found on an $s d$ wing is shown in Figure 5D. The ectopic bristle has the characteristic appearance of a sensory bristle, including a cuticular socket. Ectopic bristles seen on $s d^{+}$mutant wings do not appear to replace the campaniform sensilla, nor are they restricted to wing veins. The wing defects described above suggest that loss of $s d^{+}$function has different consequences in cells that form the dorsal and ventral surfaces of the wing blade than in cells that form the wing margin.

\section{sd transcripts and an sd enhancer trap are expressed in the nervous system of embryos}

An enhancer trap screen designed to identify genes expressed in the chemosensory organs of the adult fly identified an $s d$ mutant, designated ETX4, that has an insertion of a $P[r y+1 a c Z]$ transposon within the $s d$ transcription unit (see above). We have analyzed the pattern of $\beta$-galactosidase enzyme activity and protein localization in the ETX4 strain. The expectation of this approach is that the pattern of $\beta$-galactosidase expression will parallel the pattern of $s d$ transcript accumulation reflecting the influence of $s d$ regulatory sequences upon the expression of the reporter gene (O'Kane and Gehring 1987; Bellen et al. 1989; Wilson et al. 1989). To test this assumption, we examined the tissue distribution of $s d$ transcripts, using a $1.5-\mathrm{kb}$ fragment of the E21 cDNA clone labeled with digoxygenin as a hybridization probe (Tautz and Pfeifle 1989). This probe contains sequences common to all cDNA clones that we have characterized and is therefore expected to hybridize with all $s d$ transcripts (Campbell et al. 1991). The pattern of $s d$ transcripts and $\beta$-galactosidase localization coincide with 


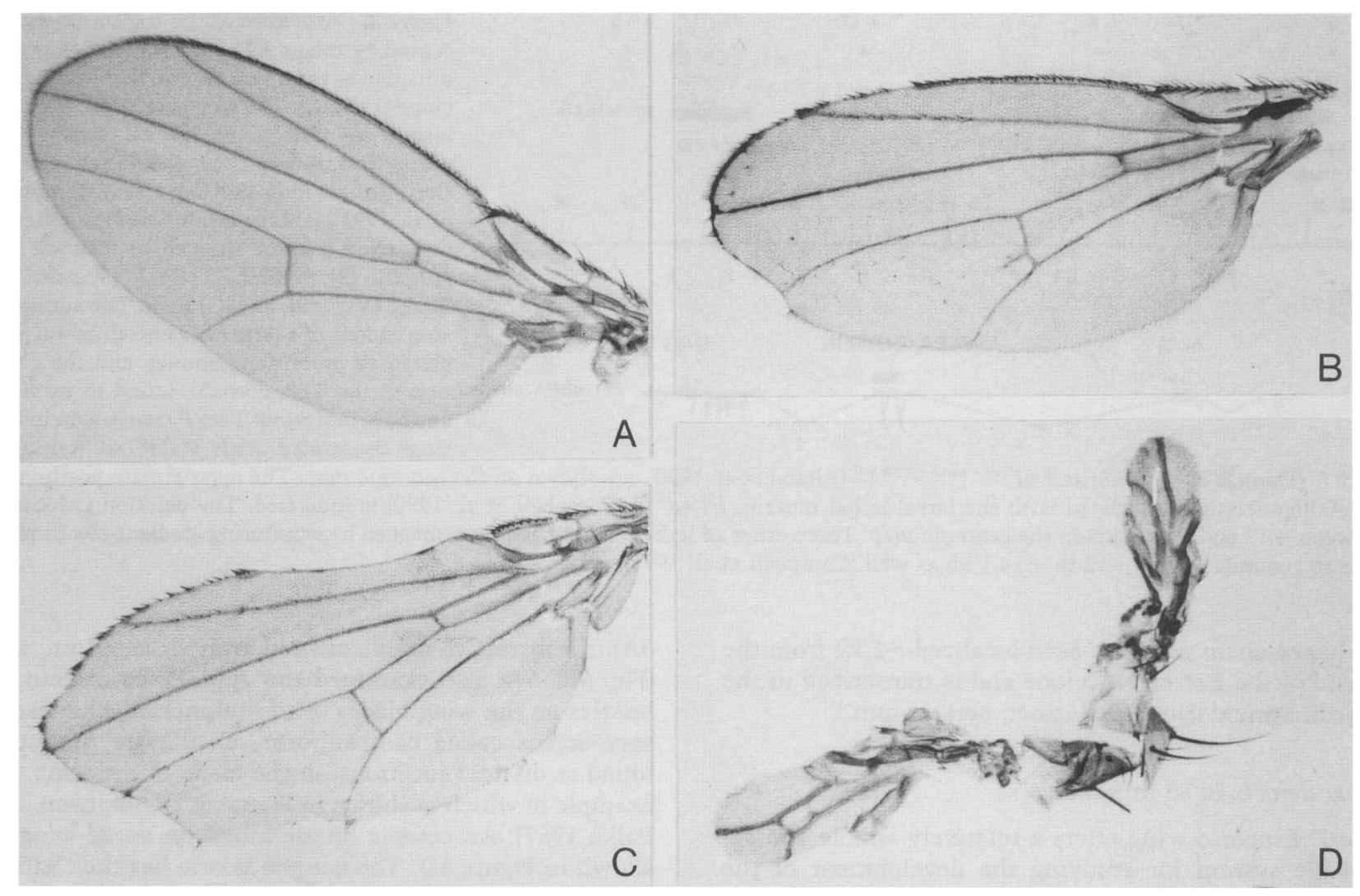

Figure 4. Viable $s d$ mutations affect the development of the wing in an allele-specific manner. Wings are from stocks of the indicated genotype: $(A)$ Canton-S, wild type; $(B) s d^{r y 2216.853} ;(C) s d^{2} ;(D) s d^{58 d}$ (two wings are mounted at right angles to each other in $\left.D\right)$. Further information about these alleles can be found in Campbell et al. (1991). Note the presence of ectopic bristles on the distal wing blades of $s d^{r y 2216-853}$ and $s d^{2}$. All wings are shown at the same magnification.

each other in the stages and tissues that we have examined. We interpret this result to mean that expression of the reporter gene is controlled by $s d$ regulatory sequences in the ETX4 strain and thus serves as an easily assayable marker for the tissue- and stage-specific expression of this gene. The signals observed with digoxygenin-labeled probes for $s d$ transcripts were generally weaker and more diffuse than the $\beta$-galactosidase patterns observed in the ETX4 strain. Therefore, in this paper we have focused on the staining pattern of the $s d$ enhancer trap strain.

Expression of the reporter gene in ETX4 embryos is first detected in the cephalic neuroblasts of embryos during germ-band elongation in stage 9 (staging is according to Campos-Ortega and Hartenstein 1985). $\beta$-Galactosidase continues to be expressed at low levels in the CNS during the remainder of embryogenesis. Staining in the ventral nerve cord seems also to include the superficially lying sheath cells. Expression in the PNS is first seen during germ-band retraction (late stage 11), a time when the precursors of the nervous system can first be detected by anti-horseradish peroxidase antibodies (Jan and Jan 1982). By stage 14, intense staining for $\beta$-galactosidase is observed in the sense organs of the trunk and the antennomaxillary complex (Fig. 6A). A similar pattern of $s d$ transcripts is detected with a digoxygenin-labeled
cDNA probe at a comparable stage of development, shown in Figure 6B. The stage 14 embryo in Figure 6B was photographed at a more dorsal plane than the embryo in Figure 6A, to show the accumulation of $s d$ transcripts that we observe in the supraesophageal ganglion (the reporter gene also stains this region in ETX4 embryos). At a later stage of germ-band retraction (stage 16), reporter gene activity is also seen in a dorsal cluster of peripheral sense organs and in sensory organs of the gnathal buds (Fig. 6C). The lateral and ventral sense organs in the trunk region are also expressing the reporter gene in stage 16 (Fig. 6D). Intense staining of the antennomaxillary complex and the clypeolabral sense organs occurs during head involution (stages 15 and 16).

The expression of the $s d$ reporter gene in the sensory nervous system was examined further by looking at double mutants that were homozygous for ETX4 and the daughterless $(\mathrm{da})$ mutation. $d a^{+}$function is required zygotically for the development of the PNS, as well as maternally for sex determination and dosage compensation, and $d a$ mutations remove all sense organs of the embryo (Caudy et al. 1988). The da gene encodes a helix-loophelix (HLH) protein that interacts with HLH proteins encoded by the achaete-scute complex in the regulation of neurogenesis, potentially via heterodimer interactions (Cabrera and Alonso 1991). In ETX4 · da mutant em- 

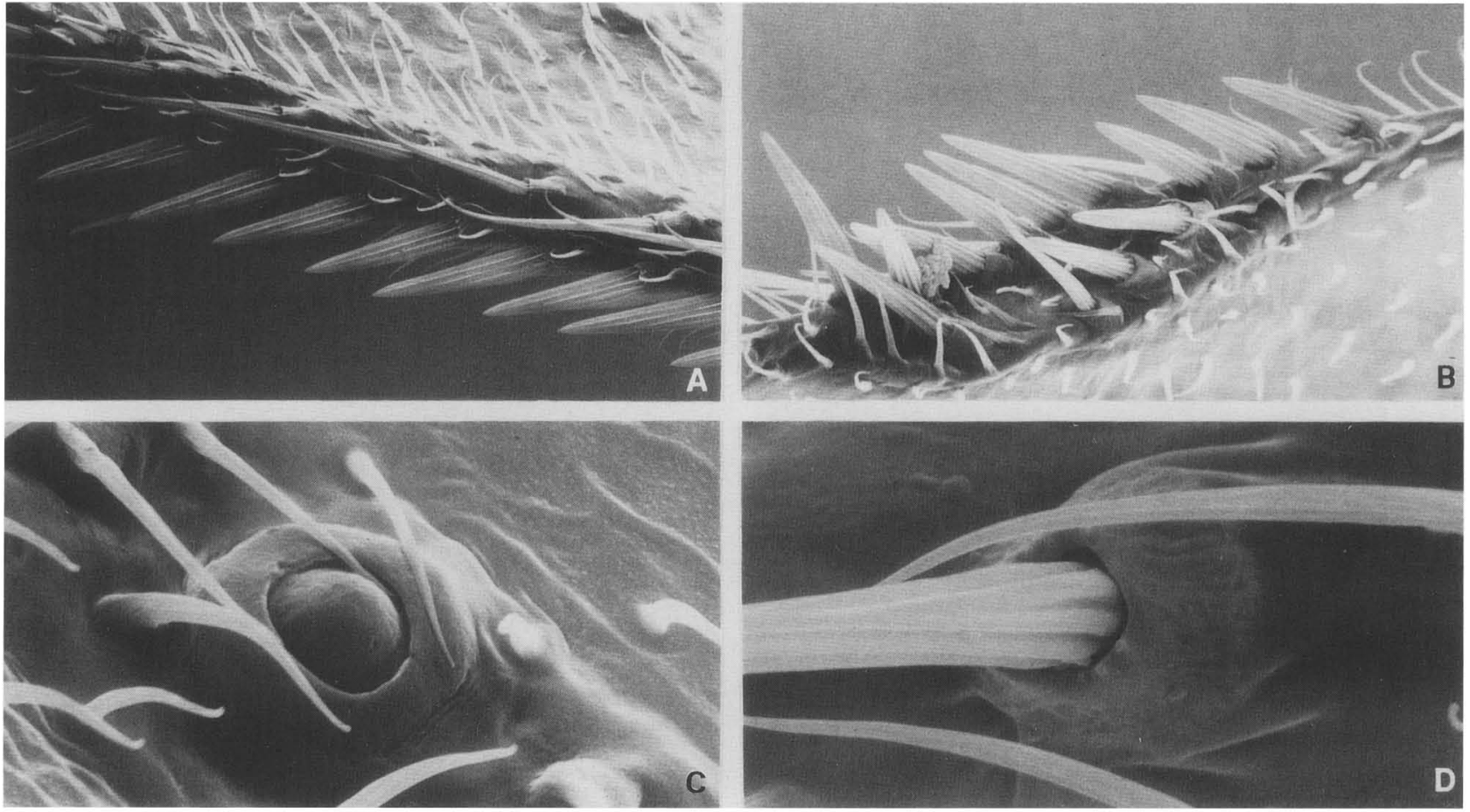

Figure 5. Sensory structures on the adult wing. SEMs of the anterior wing margin are shown from stocks of the indicated genotype: (A) Canton-S, wild type; $(B) s d^{2}$. A campaniform sensilla found on a wild-type wing is shown in $C$, and an ectopic macrochaeta found on a $s d^{2}$ wing is shown in $D$.

bryos, no reporter gene activity was seen in regions normally corresponding to the PNS nor were there detectable $s d$ transcripts in these regions (data not shown). These results suggest that $s d^{+}$activity is required later in these regions of the embryo than $\mathrm{da}^{+}$activity. However, some staining persisted in the cerebral hemispheres and ventral nerve cord in the double mutant embryos. The residual activity that we observe in the CNS may be explained by the observation that mutations in the $d a$ gene have variable effects in the CNS (Campos-Ortega and Jan 1991).

Preliminary observations of the PNS in a larval-lethal $s d$ mutant, $\left.\left[1(1) s d^{3 L}\right]\right)$, using the neuron-specific antibody $\mathrm{mAb} 22 \mathrm{C} 10$, indicate abnormalities in the number and position of embryonic sensory organs. These effects may account for the lethality observed in this mutant.

\section{Expression of an sd enhancer trap line in the larval CNS}

During the third-larval instar, strong staining for $s d$ reporter gene activity is observed in the optic proliferation centers of the brain as well as other discrete cells located in the cerebral hemispheres, and in a subset of cells of the ventral ganglion (Fig. $6 \mathrm{E}$ ). We believe that these cells are unlikely to be neuroblasts, on the basis of comparisons of camera lucida drawings of the stained profiles in the ventral nerve cord with data from Truman and Bate (1988). We speculate that most of the staining cells are sheath cells or glia. In addition, several deep foci were observed that are presumed to be neuronal cells because of their position (these lie outside the boundaries of the optic lobes), as shown in Figure 6F. When the entire larval CNS is considered, smaller subsets of cells stain positively for the reporter gene in the first- and second-larval instars than in the third larval instar. The number of stained cells then decreases in the CNS during pupal development.

\section{Expression of an sd enhancer trap line in imaginal discs}

Precursor cells for most of the adult tissues are set aside during embryogenesis in structures called imaginal discs. We were interested in exploring the relationship between the pattern of reporter gene expression in the wing disc and the pattern of defects in sd mutants. The wing disc gives rise to the structures of the wing and part of the thorax, as described in the fate map of Bryant (1975). During the third-larval instar, staining for the reporter gene in the ETX4 strain is concentrated in the regions of the wing disc that give rise to the adult wing blade, the scutellum, and the mesopleura, as shown in Figure 6G. The pattern of expression thus includes regions of the disc that develop into defective adult structures in $s d$ mutants (loss or gain of sensory organs and epidermal cells in the wing blade and uplifted postscutellar bristles on the thorax).

In the eye-antennal disc, $s d$ reporter gene expression appears to be turned on immediately behind the morpho- 


\section{Campbell et al.}
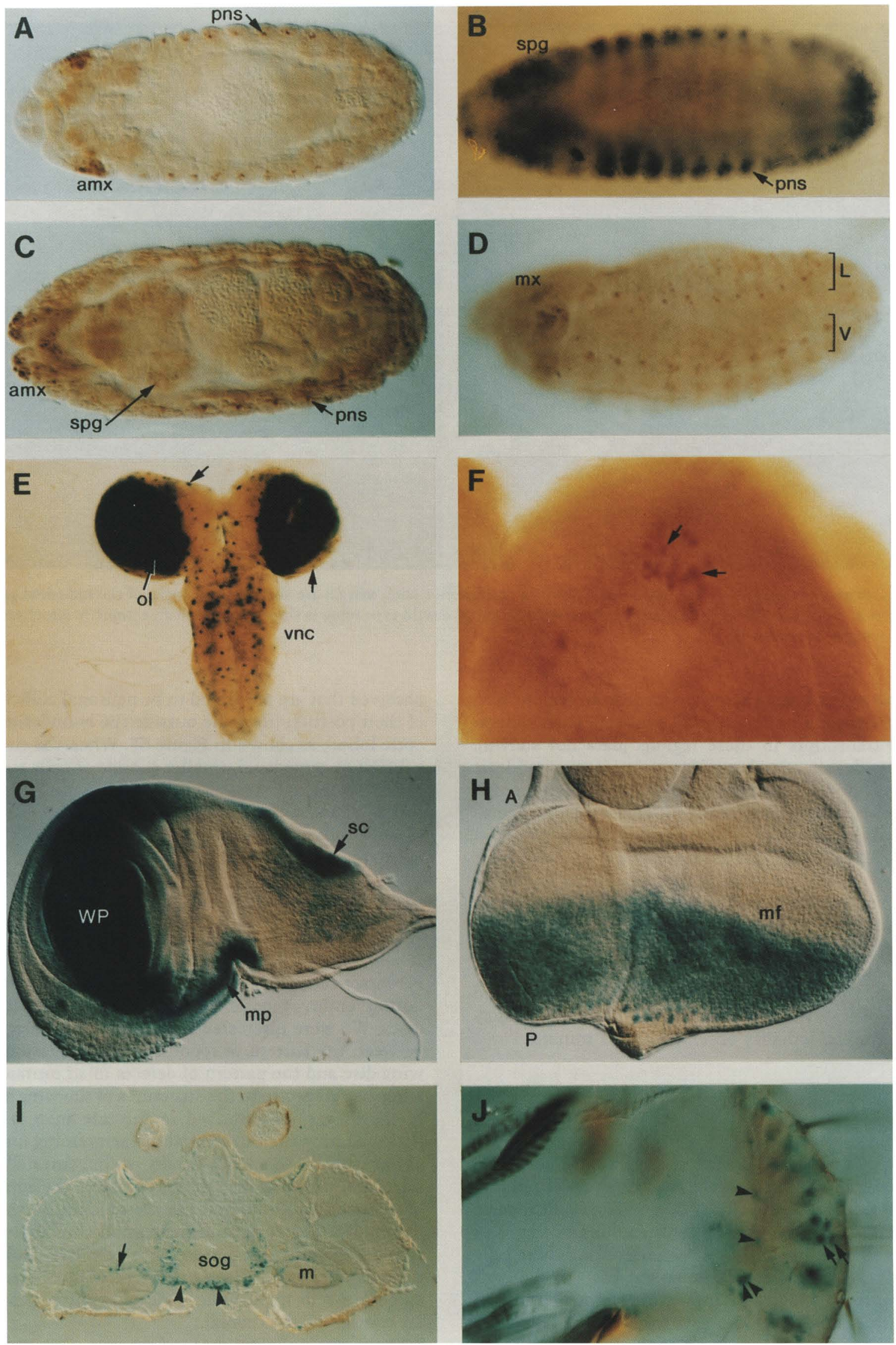

Figure 6. (See facing page for legend.) 
genetic furrow as it moves across the developing eye disc during the third-larval instar (Fig. $6 \mathrm{H}$ ). The morphogenetic furrow demarcates a cellular process of differentiation, with cells posterior to the furrow being more differentiated than those anterior to it (Tomlinson and Ready 1987). A slight roughening of the adult eye was reported concerning the original $s d$ mutant, which may reflect a role for the gene in eye development (Lindsley and Zimm 1990). In the future, mosaic studies with null alleles may allow us to define a role for $s d$ in eye development.

All of the other larval imaginal discs, except for the labial disc, also show reporter gene staining in specific regions during the third-larval instar. The absence of expression in the labial disc may be explained by the observation that this tissue (which later forms the adult proboscis) differentiates later than the other imaginal discs, as assessed by staining of neurons with the antibody mAb22C10 (K. Ray, pers. comm.).

\section{Expression of an sd enhancer trap strain in the brain and chemosensory organs of the adult fly}

Expression of the $s d$ reporter gene can be observed in discrete regions of the adult brain, an example of which is shown in Figure 6I. In this section, a number of cell bodies are stained in the subesophageal ganglion, a region thought to be important for the processing of gustatory sensory information (Nayak and Singh 1985). Small clusters of nuclei lying medial to the antennal neuropile and within the lobular plate are also labeled. Cell bodies in the calyx of the mushroom bodies also express the reporter gene. More dorsally, in the protocerebrum, two symmetrically distributed groups of cell bodies were also stained.

Because several $s d$ alleles show defects in taste behavior, we examined whole-mount preparations of head sense organs for evidence of $s d$ gene expression in the adult PNS (Anand et al. 1990). Gustatory and olfactory adult sensory organs are located on the proboscis and antennae, respectively. A typical gustatory sensillum on the proboscis of an adult is composed of eight cells (five neuronal and three support cells), and four of these neurons serve a taste function (Falk et al. 1976; Nayak and Singh 1983). On the proboscis of an ETX4 adult, two cells are stained by the reporter gene in each sensillum (see Fig. 6J). Comparison of the position of these cells with whole mounts stained with the neuron-specific antibody mAb22C10 suggests that these cells are non-neuronal and are probably the sheath cell and the glial cell. In addition, a few cells closely apposed to the branches of the taste nerves also show reporter gene activity (arrows, Fig. 6J).

A subset of cells in the olfactory sensilla and the sacculus of the antenna are sites of reporter gene staining. Reporter gene activity is also seen in adult retinal photoreceptor cells, in discrete foci of the ventral ganglion, and in the tergal depressor of the trochanter (the jump muscle of the mesothoracic leg). Surface hairs located all over the cuticle of the adult also stain positively for the reporter gene enzyme activity.

\section{Discussion}

We have presented evidence that the $s d$ gene encodes a protein homologous to a human transcriptional enhancer factor, TEF-1. The amino acid sequence of the predicted $s d$ protein sequence includes a highly conserved sequence recently named the TEA domain, which seems to be an evolutionarily conserved DNA-binding motif (Bürglin 1991). This domain has been found in three other proteins to date, all of which appear to be transcription factors on genetic or biochemical grounds (Mirabito et al. 1989; Laloux et al. 1990; Xiao et al. 1991).

Hypomorphic and lethal $s d$ mutants map within or near the $\sim 12-\mathrm{kb} s d$ primary transcription unit described herein. One of these, an early larval-lethal allele, is associated with a small deletion that interrupts the coding region of the E21 cDNA clone, implying that the Drosophila TEF-1 homolog plays an essential role in early development. An $s d$ enhancer trap strain exhibits temporal and spatial developmental specificity suggestive of a role

Figure 6. Localization of reporter gene activity in the enhancer trap allele $s d^{P(z y+l a c Z+E T X 4)}$ at different stages of development. $\beta$-Galactosidase was detected either by monoclonal antibody staining or by staining for enzyme activity (see Materials and methods). Anterior is to the left in the embryo panels $(A-D)$. Staging of embryos was according to Campos-Ortega and Hartenstein (1985). $(A)$ Dorsal view of an embryo at the beginning of dorsal closure (stage 14). The PNS (pns) and antennomaxillary complex (amx) are stained intensely. $(B)$ Dorsal view of a stage 14 embryo, showing the distribution of $s d$ transcripts detected by a digoxygenin-labeled E21 cDNA probe. Labeling is seen in the PNS (pns) and in the supraesophageal ganglion (spg). (C) Dorsal view of an embryo at stage 16 after head involution shows labeling in the anterior sense organs (amx), the PNS (pns), and the supraesophageal ganglion (spg). (D) A lateral view of a stage 16 embryo shows reporter gene expression localized in the ventral (V) and lateral (L) sense organs of the PNS. Staining is also observed in the sense organs of the gnathal regions $(\mathrm{mx})$. $(E)$ Localization of reporter gene activity in the third-larval instar brain. Histochemical staining for $\beta$-galactosidase activity shows activity in the optic lobes (ol) as well as in discrete cells of the cerebral hemispheres (arrows) lying outside of the optic lobes and in specific cells of the ventral nerve cord (vnc). (F) Immunological detection of $\beta$-galactosidase expressed by the reporter gene is also localized to a group of cells in the interior of the cerebral hemispheres in the brain (arrows). This photograph has been enlarged to focus on this part of the brain. (G) Histochemical detection of the reporter gene in a third-instar wing disc. Regions destined to become the presumptive wing blade (WP), the scutellum (sc), and the mesopleura (mp) according to Bryant (1975) show strong staining. $(H)$ Eye region of an ETX4 cephalic disc stained for $\beta$-galactosidase activity. Staining appears in ommatidia developing behind the morphogenetic furrow $(\mathrm{mf})$. The anterior $(\mathrm{A})$ and posterior $(\mathrm{P})$ orientation are shown. $(I)$ Reporter gene activity in the adult head. A horizontal section $(8 \mu \mathrm{m})$ through the brain at the level of the subesophageal ganglion (sog) is shown. (/) Whole mount of an adult ETX4 proboscis, showing $\beta$-galactosidase activity in cells of the gustatory sensilla (arrows). In addition, certain cells closely associated with the branches of the labial nerve are also stained (arrowheads). 
for this gene in the differentiation of the larval and adult nervous system.

\section{Is sd a functional homolog of TEF-1?}

An extraordinary degree of sequence conservation is found between the TEA domains in the $s d$-predicted protein sequence and TEF-1, and high conservation is observed across the entire predicted sequences. Sequence conservation of this magnitude, between genes from such evolutionarily distant organisms, implies that the evolution of these proteins has been tightly constrained, perhaps by the necessity to conserve multiple sites for independent protein-DNA and protein-protein interactions.

Little is known about the normal cellular functions performed by $T E F-1$. The sequence conservation between $T E F-1$ and $s d$ implies that the two genes are likely to be functional homologs. What assumptions of this hypothesis can we test? First, it needs to be demonstrated directly that the $s d$ protein can act as a sequencespecific DNA-binding protein and can bind sites similar to those recognized by $T E F-1$. Human $T E F-1$ protein binds two distinct sequence motifs within the SV40 enhancer (the SphI and GT-IIC sites; Davidson et al. 1988). Sequences similar to the GT-IIC site of the SV40 enhancer are found in the Ty transposable element in yeast, and modified versions exist in many retroviral enhancers (Company and Errede 1988).

$T E F-1$ has the potential to act either as an activator or repressor of promoter activity, depending on the presence or absence of a limiting, cell-specific factor necessary for the activation function that has been named TIF (transcriptional intermediary factor). Although TIF has not yet been isolated, the site important for its interaction with TEF-1 appears separable from the DNA-binding TEA domain (Xiao et al. 1991). Other examples of transcription factors capable of acting either as repressors or activators of promoter activity, depending on cellular context, have recently been described (Damm et al., 1989; Steingrimsson et al. 1991). Powerful genetic approaches for identification of genes whose products could interact with $s d$ have been developed for Drosophila (Brand and Campos-Ortega 1989; Xu et al. 1990). Conceivably, these might uncover the Drosophila equivalent of TIF, as well as other molecular components of transcriptional complexes that include the $s d$ protein. There is already some genetic evidence that $s d$ might interact with the large subunit of RNA polymerase II, based on phenotypic enhancement in transheterozygote combinations with a mutant allele of this gene, $U b 1$ (Mortin and Lefevre 1981). It will also be of interest to determine whether $s d$ might be a member of a multigene family, analogous to the rel/NF- $\mathrm{B}$ family of transcriptional regulators (Kieran et al. 1990). If the TEF-1 and scalloped genes are indeed functionally equivalent, then we would expect TEF-1 to function in the development of the human nervous system. One approach to this question would be to identify a mouse homolog of TEF-1, thus enabling a genetic dissection of the gene in a mam- malian system and the localization of the gene products during development.

\section{Multiple roles of the sd gene in Drosophila development}

Many genes regulating development encode sequencespecific DNA-binding proteins that are presumed to act as combinatorial transcription factors, coordinating the expression of batteries of other genes. Evidence has been presented that suggests that the $s d$ gene encodes a transcription factor required in a number of different cell types, some of which are components of the nervous system. Genetic data suggest that distinct essential functions are provided by the $s d^{+}$gene at two times in development (at or before the first-instar larval and pupal stages of development; Campbell et al. 1991). We have examined the pattern of $s d$ transcript accumulation and expression of an $s d$ enhancer trap strain during embryogenesis for clues to the early function. The transcript and reporter gene patterns show that the gene is transcribed in precursor cells of the larval nervous system. Preliminary analysis of the nervous system in early $s d$ lethal mutants indicates that subtle defects in larval sensory organs occur in this genetic background. These mutant larvae may be impaired in aspects of sensory function necessary for sustaining larval viability. Conceivably, chemosensory functions required for normal feeding behavior could be defective in these mutant larvae. This is a likely prospect, given the adult gustatory phenotype of viable $s d$ mutants (Anand et al. 1990). These observations suggest that $s d^{+}$activity is required for the proper differentiation of sensory organs.

$s d^{+}$function is also required during larval development for normal development of the wing from an imaginal disc (James and Bryant 1981; Simpson et al. 1981). An $s d$ enhancer trap strain expresses the reporter gene in specific regions of the imaginal wing disc, including the region destined to become the adult wing (Bryant 1975). Hypomorphic $s d$ mutants are associated with elevated cell death in larval wing discs, suggesting a dosage-sensitive requirement for $s d^{+}$expression to promote cell viability (James and Bryant 1981). Regulated cell death is recognized as an important developmental regulatory mechanism, particularly in the development of the nervous system (Truman 1990). In the eye disc of Drosophila, for example, cell death eliminates cells that fail to establish appropriate intercellular contacts (Cagan and Ready 1989). A requirement for $s d^{+}$function in precursor cells of the wing margin could account for the margin-degeneration defects of $s d$ mutants. However, it fails to explain an allele-specific aspect of the mutant phenotype, namely the induction of ectopic sensory organs on the wing blade. Perhaps the sd protein functions as part of a transcriptional switch mechanism used in the establishment or maintenance of specific cell fates. According to this model, $s d$ could participate in qualitatively distinct transcriptional switches, depending on its interactions with cell-specific cofactors. Under such circumstances, hypomorphism for $s d^{+}$activity might have 
quite different phenotypic consequences in different developmental contexts. Specific cells of the adult taste receptors (probably glial and sheath cells) are stained in our $s d$ enhancer trap strain, as well as regions of the brain associated with the processing of gustatory information. These observations may mean that $s d^{+}$products are required to maintain specific glial or sheath cell patterns of gene expression in sensory organs of adults.

In summary, we have provided evidence that the $s d^{+}$ gene encodes a new member of the TEA domain family of DNA-binding proteins. Phenotypic analysis of $s d \mathrm{mu}-$ tants and chararacterization of the expression pattern of an $s d$ enhancer trap line suggest that the products of this gene are required in specific populations of cells in the nervous system and imaginal discs during development. Further genetic and biochemical experiments will enable us to test these general conclusions, to identify other genes that interact with $s d$, and to understand how $s d^{+}$ expression is spatially and temporally regulated.

\section{Materials and methods}

Fly strains

The $s d r y^{+E T X 4}$ allele was isolated in a screen for enhancer-trap $P$-insertions on the X chromosome (Anand et al. 1990). $s d$ visible alleles used for the analysis of the wing phenotype and $s d$ lethal alleles used for molecular analysis are described in Campbell et al. (1991). The strain $d a^{K X} b$ pr cn bw/CyO was provided by J.A. Campos-Ortega (University of Cologne, Germany).

\section{Light microscopy and SEM analysis of wings}

Wings were excised for visual analysis from etherized flies, mounted directly in Permount on slides, and flattened overnight with 50-gram weights. Wings to be mounted for SEM were excised from flies that had been dehydrated for $24 \mathrm{hr}$ before mounting directly onto stubs and sputter-coated with gold.

\section{Histochemical and immunological detection of sd reporter gene activity}

$\beta$-Galactosidase activity was detected using $\mathrm{X}$-gal as a substrate by standard procedures (Wilson et al. 1989). Adult whole mounts were prepared by freezing in liquid nitrogen in a drop of $45 \%$ Ficoll. A preliminary slice was then made with a razor blade, and $8-\mu \mathrm{m}$ tissue sections were cut with a cryostat. The tissue sections were then fixed for $10 \mathrm{~min}$ in $1 \%$ gluteraldehyde in PBS and incubated overnight at $37^{\circ} \mathrm{C}$ in staining solution. Larval brain and imaginal discs were also fixed in $1 \%$ gluteraldehyde in $100 \mathrm{~mm}$ cacodylate buffer prior to staining. After staining, tissues were washed in $70 \%$ alcohol and mounted in $95 \%$ glycerol. For permanent preparations, samples were dehydrated through an alcohol series and mounted in DePex.

Monoclonal antibodies to Escherichia coli $\beta$-galactosidase were generously provided by $\mathrm{R}$. White (University of Cambridge, UK). Antigen-antibody binding was detected using a biotinylated anti-mouse IgG and the streptavidin-HRP conjugate (Elite kit, Vectastain).

\section{Detection of sd transcripts}

A 1.5-kb fragment was PCR amplified from the E21 cDNA using primers that bracket the end of the third exon to midway through the twelfth exon, including the entire predicted coding sequence. The fragment was labeled with digoxygenin$11 \mathrm{dUTP}$, following the manufacturer's instructions (Genius kit, Boehringer Mannheim). Hybridizations to embryos were carried out as described by Tautz and Pfeifle (1989). After the staining reaction, embryos were dehydrated and mounted in DePex.

\section{Genomic and $c D N A$ sequence analysis}

Genomic and cDNA restriction fragments were isolated from clones described previously (Campbell et al. 1991) and subcloned into the pEMBL phagemid vector (Dente and Cortese 1983) by standard procedures (Maniatis et al. 1982). Sequencing constructs were made by the exonuclease III deletion method (Henikoff 1984). Single-strand template DNA was isolated for sequencing reactions by standard methods, using the M13K07 helper phage. Template DNA was sequenced by the dideoxy method (Sanger et al. 1977) using T7 DNA polymerase (Pharmacia). The E2 1 cDNA clone was sequenced in both directions and instances of sequence ambiguity due to compression artifacts were checked by reactions utilizing the 7-deaza-dGTP analog. Genomic DNA was sequenced in one direction only.

\section{Acknowledgments}

We thank T. Bürglin, for pointing out to us that the similarity of the predicted protein sequences of $s d$ and TEF-1 extended over the entire coding region. We received valuable advice during the course of these studies from Mark Peifer, Steve Daniels, Dan Curtis, Welcome Bender, and Paul Betts. The staff of the electron microscopy facility at the University of Connecticut provided training and assistance for the wing studies. Helpful comments on the manuscript were provided by Jim Jaynes, Danesh Moazed, Pat O'Farrell, Mark Peifer, and Tony Shermoen. These investigations were supported by research grant GM09886 from the U.S. Public Health Service, and by a grant from the Tata Institute of Fundamental Research.

The publication costs of this article were defrayed in part by payment of page charges. This article must therefore be hereby marked "advertisement" in accordance with 18 USC section 1734 solely to indicate this fact.

\section{References}

Anand, A., J. Fernandes, M.C. Arunan, S. Bhosekar, A. Chopra, N. Dedhia, K. Sequiera, G. Hasan, M.J. Palazzolo, K.V. Raghavan, and V. Rodrigues. 1990. Drosophila "enhancertrap" transposants: Gene expression in chemosensory and motor pathways and identification of mutants affected in smell and taste ability. J. Genet. 69: 151-168.

Bellen, H.J., C.J. O'Kane, C. Wilson, U. Grossnicklaus, R.K. Pearson, and W.J. Gehring. 1989. P-element mediated enhancer detection: A versatile method to study development in Drosophila. Genes \& Dev. 3: 1288-1300.

Bodmer, R., S. Barbel, S. Sheperd, J.W. Jack, L.Y. Jan, and Y.N. Jan. 1987. Transformation of sensory organs by mutations of the cut locus of Drosophila melanogaster. Cell 51: 293-307.

Brand, M. and J.A. Campos-Ortega. 1989. Second site modifiers of the split mutation of Notch define genes involved in neurogenesis in Drosophila melanogaster. Wilhelm Roux's Arch. Dev. Biol.198: 275-285.

Brawerman, B. 1989. mRNA decay: Finding the right targets. Cell 57: 9-10.

Brown, N.H. and F.C. Kafatos. 1988. Functional cDNA libraries from Drosophila embryos. J. Mol. Biol. 203: 425-437. 
Brown, N.H., D.L. King, M. Wilcox, and F.C. Kafatos. 1989. Developmentally regulated alternative splicing of Drosophila integrin PS2a transcripts. Cell 59: 185-195.

Bryant, P.J. 1975. Pattern formation in the imaginal wing disc of Drosophila melanogaster: Fate map, regeneration and duplication. J. Exp. Zool. 193: 49-78.

Bürglin, T.R. 1991. The TEA domain: A novel, highly conserved DNA-binding motif. Cell 66: 11-12.

Cabrera, C.V. and M.C. Alonso. 1991. Transcriptional activation by heterodimers of the achaete scute and daughterless gene products of Drosophila. EMBO J. 10: 2965-2973.

Cagan, R.L. and D.F. Ready. 1989. The emergence of order in the Drosophila pupal retina. Dev. Biol. 136: 346-362.

Campbell, S.D., A. Duttaroy, A.L. Katzen, and A. Chovnick. 1991. Cloning and characterization of the scalloped gene of Drosophila melanogaster. Genetics 127: 367-380.

Campos-Ortega, J.A. and V. Hartenstein. 1985. The embryonic development of Drosophila melanogaster. Springer-Verlag, Berlin.

Campos-Ortega, J.A. and Y.N. Jan. 1991. Genetic and molecular bases of neurogenesis in Drosophila melanogaster. Annu. Rev. Neurosci. 14: 399-420.

Campos-Ortega, J.A. and E. Knust. 1990. Genetics of early neurogenesis in Drosophila melanogaster. Annu. Rev. Genetics 24: $387-407$.

Caudy, M., H. Vassin, M. Brand, R. Tuma, L.Y. Jan, and Y.N. Jan. 1988. daughterless, a Drosophila gene essential for both neurogenesis and sex determination, has sequence similarities to myc and the achaete-scute complex. Cell 55: 10611067.

Company, M. and B. Errede. 1988. A Ty1 cell-type-specific regulatory sequence is a recognition element for a constitutive binding factor. Mol. Cell. Biol. 8: 5299-5309.

Damm, K., C.C. Thompson, and R.M. Evans. 1989. Protein encoded by v-erbA functions as a thyroid-hormone receptor antagonist. Nature 339: 593-597.

Daniels, S.B., M. McCarron, C. Love, and A. Chovnick. 1985. Dysgenesis-induced instability of rosy locus transformation in Drosophila melanogaster: Analysis of excision events and the selective recovery of control element deletions. Genetics 109: 95-117.

Davidson, I., J.H. Xiao, R. Rosales, A. Staub, and P. Chambon. 1988. The HeLa cell protein TEF-1 binds specifically and cooperatively to two SV40 enhancer motifs of unrelated sequence. Cell 54: 931-942.

Dente, L. and R. Cortese. 1983. pEMBL: A new family of singlestranded plasmids for sequencing DNA. Nucleic Acids Res. 11: 1645-1655.

Dickinson, M.H. and J. Palka. 1987. Physiological properties, time of development, and central projection are correlated in the wing mechanoreceptors of Drosophila. I. Neurosci. 7: 4201-4208.

Engels, W. R. 1989. P elements in Drosophila melanogaster. In Mobile DNA (ed. D. Berg and M. Howe), pp. 437-487. American Society for Microbiology, Washington, D.C.

Falk, R., N. Bleiser-Aviv, and J. Atidia. 1976. Labellar taste organs of Drosophila melanogaster. J. Morphol. 150: 327-331.

Fleming, R.J., T.N. Scottgale, R.J. Diederich, and S. ArtavanisTsakonas. 1990. The gene Serrate encodes a putative EGFlike transmembrane protein essential for proper ectodermal development in Drosophila melanogaster. Genes \& Dev. 4: 2188-2201.

Garcia Alonso, L.A. and A. Garcia-Bellido. 1988. Extramacrochaetae, a trans-acting gene of the achaete-scute complex of Drosophila involved in cell communication. Wilhelm Roux's Arch. Dev. Biol. 197: 328-338.
Garcia-Bellido, A. and J.R. Merriam. 1971. Parameters of the wing imaginal disc development of Drosophila melanogaster. Dev. Biol. 24: 61-87.

Gruneberg, H. 1929. Ein Beitrag zur Kenntis der Rontgenmutationen des X-chromosoms von Drosophila melanogaster. Biol. Zentralbl. 49: 680-694.

Hartenstein, V. and J.W. Posakony. 1989. Development of adult sensilla on the wing and notum of Drosophila melanogaster. Development 107: 389-405.

-1990. Sensillum development in the absence of cell division: The sensillum phenotype of the Drosophila mutant string. Dev. Biol. 138: 147-158.

Henikoff, S. 1984. Unidirectional digestion with exonuclease III creates targeted breakpoints for DNA sequencing. Gene 28: 351-359.

James, A.A. and P.J. Bryant. 1981. Mutations causing pattern deficiencies and duplications in the imaginal wing disk of Drosophila melanogaster. Dev. Biol. 85: 39-54.

Jan, L.Y. and Y.N. Jan. 1982. Antibodies to horseradish peroxidase as specific neuronal markers in Drosophila and in grasshopper embryos. Proc. Natl. Acad. Sci. 79: 2700-2704.

Kieran, M., V. Blank, F. Logeat, J. Vandekerckhove, F. Lottspeich, O. Le Bail, M.B. Urban, P. Kourilsky, P.A. Baeuerle, and A. Israel. 1990. The DNA binding subunit of NF- $\kappa B$ is identical to factor $\mathrm{KBFl}$ and homologous to the rel oncogene product. Cell 62: 1007-1018.

Laloux, I., E. Dubois, M. Dewerchin, and E. Jacobs. 1990. TEC1, a gene involved in the activation of Ty1 and Ty1-mediated gene expression in Saccharomyces cerevisiae: Cloning and molecular analysis. Mol. Cell. Biol. 10: 3541-3550.

Lindsley, D.L. and G. Zimm. 1990. The genome of Drosophila melanogaster. Drosophila Inf. Serv. 68: 193.

Maniatis, T., E.F. Fritsch, and J. Sambrook. 1982. Molecular cloning: A laboratory manual. Cold Spring Harbor Laboratory, Cold Spring Harbor, New York.

Mirabito, P.M., T.H. Adams, and W.E. Timberlake. 1989. Interactions of three sequentially expressed genes control temporal and spatial specificity in Aspergillus development. Cell 57: 859-868.

Mortin, M.A. and G. Lefevre. 1981. An RNA polymerase II mutation in Drosophila melanogaster that mimics Ultrabithorax. Chromosoma 82: 237-247.

Mount, S.M. 1982. A catalogue of splice junction sequences. Nucleic Acids Res. 10: 459-471.

Murray, M.A., M. Schubiger, and J. Palka. 1984. Neuron differentiation and axon growth in the developing wing of Drosophila melanogaster. Dev. Biol. 104: 259-273.

Nayak, S.V. and R.N. Singh. 1983. Sensilla on the tarsal segments and mouthparts of adult Drosophila melanogaster. Meigen Int. J. Insect Morphol. Embryol. 12: 273-291.

- 1985. Primary projection patterns from the labella to the brain of Drosophila melanogaster. Meigen Int. I. Insect Morphol. Embryol. 14: 115-129.

O'Kane, C.J. and W.J. Gehring. 1987. Detection in situ of genomic regulatory elements in Drosophila. Proc. Natl. Acad. Sci. 84: 9123-9127.

Palka, J., P.A. Lawrence, and H.S. Hart. 1979. Neural projection patterns from homeotic tissue of Drosophila studied in bithorax mutants and mosaics. Dev. Biol. 69: 549-575.

Perrimon, N. and D. Smouse. 1989. Multiple functions of a Drosophila homeotic gene, zeste-white 3, during segmentation and neurogenesis. Dev. Biol. 135: 287-305.

Poodry, C.A. 1975. A temporal pattern in the development of sensory bristles in Drosophila. Wilhelm Roux's Arch. Dev. Biol. 178: 203-213.

Ripoll, P., M.E. Messal, E. Laran, and P. Simpson. 1988. A gra- 
dient of affinities for sensory bristles across the wing blade of Drosophila melanogaster. Development 103: 757-767.

Rushlow, C.A., A. Hogan, S.M. Pinchin, K.M. Howe, M. Lardelli, and D. Ish-Horowicz. 1989. The Drosophila hairy protein acts in both segmentation and bristle patterning and shows homology to N-myc. EMBO I. 8: 3095-3103.

Sanger, F.S., S. Nicklen, and A.R. Coulson. 1977. DNA sequencing with chain-terminating inhibitors. Proc. Natl. Acad. Sci. 74: 5463-5467.

Simpson, P. and C. Carteret. 1989. A study of shaggy reveals spatial domains of expression of achaete-scute alleles on the thorax of Drosophila. Development 106: 57-66.

Simpson, P., P.A. Lawrence, and F. Maschat. 1981. Clonal analysis of two wing-scalloping mutants of Drosophila. Dev. Biol. 84: 206-211.

Steingrimsson, E., F. Pignoni, G.J. Liaw, and J.A. Lengyel. 1991. Dual role of the Drosophila pattern gene tailless in embryonic termini. Science 254: 418-421.

Tautz, D. and C. Pfeifle. 1989. A non-radioactive in situ hybridization method for the localization of specific RNAs in Drosophila embryos reveals translational control of the segmentation gene hunchback. Chromosoma 98: 81-85.

Thomas, U., S.A. Speicher, and E. Knust. 1991. The Drosophila gene Serrate encodes an EGF-like transmembrane protein with a complex expression pattern in embryos and wing discs. Development 111: 749-761.

Tomlinson, A. and D.F. Ready. 1987. Neuronal differentiation in the Drosophila ommatidium. Dev. Biol. 120: 366-376.

Truman, J.W. 1990. Metamorphosis of the central nervous system of Drosophila. J. Neurobiol. 21: 1072-1084.

Truman, J.W. and M. Bate. 1988. Spatial and temporal patterns of neurogenesis in the central nervous system of Drosophila melanogaster. Dev. Biol. 125: 145-157.

Wilson, C., R.K. Pearson, H.J. Bellen, C.J. O'Kane, U. Grossniklaus, and W.J. Gehring. 1989. P-element mediated enhancer detection: An efficient method for isolating and characterizing developmentally regulated genes in Drosophila. Genes \& Dev. 3: 1301-1313.

Xiao, J.H., I. Davidson, H. Matthes, J.-M. Garnier, and P. Chambon. 1991. Cloning, expression and transcriptional properties of the human enhancer factor TEF-1. Cell 65: 551-568.

$\mathrm{Xu}, \mathrm{T}$., I. Rebay, R.J. Fleming, T.N. Scottgale, and S. ArtavanisTsakonas. 1990. The Notch locus and the genetic circuitry involved in early Drosophila neurogenesis. Genes \& Dev. 4: $464-475$. 


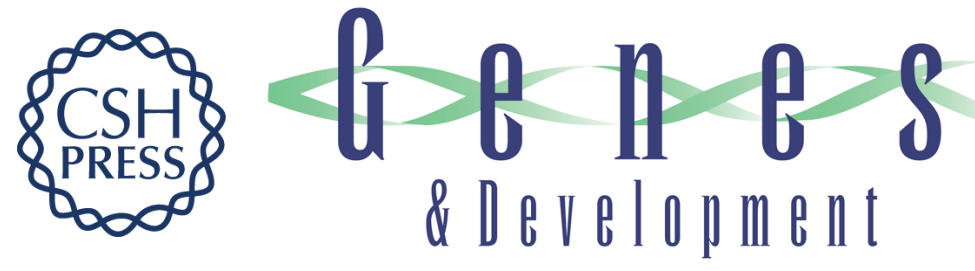

\section{The scalloped gene encodes a novel, evolutionarily conserved transcription factor required for sensory organ differentiation in Drosophila.}

S Campbell, M Inamdar, V Rodrigues, et al.

Genes Dev. 1992, 6:

Access the most recent version at doi:10.1101/gad.6.3.367

References This article cites 58 articles, 17 of which can be accessed free at: http://genesdev.cshlp.org/content/6/3/367.full.html\#ref-list-1

License

Email Alerting Service

Receive free email alerts when new articles cite this article - sign up in the box at the top right corner of the article or click here.

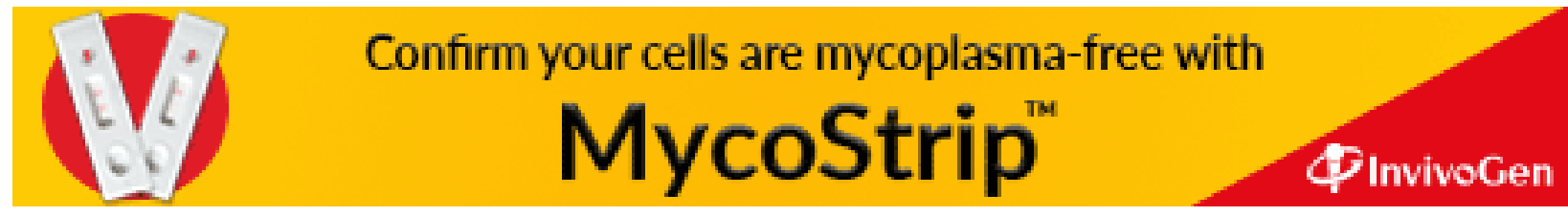

